\title{
ESTUDIO DE ALGUNAS UNIDADES LINGÜÍSTICAS DESIGNATIVAS
}

Concepción Otaola Olano

\section{INTRODUCCIÓN}

La idea de llevar a cabo este estudio surgió en el transcurso de una investigación de mayor envergadura'. Esta primera aproximación al estudio de ciertas unidades lingüisticas designativas, a pesar de ser marginal y tangencial a la investigación anteriormente aludida, no sólo por su corpus sino también por su metodología, persigue, como fin último, contribuir con esta aportación al cojunto de la investigación en curso sobre el léxico en la prensa contemporánea.

La chispa provocadora de este estudio se encuentra en la plurivalencia y el confusionismo reinante en el empleo de ciertas unidades designativas, así como la pluralidad de valores derivada de su uso y la intencionalidad subyacente.

$\mathrm{Si}$ nos centramos en las designaciones cuyo referente es la población oriunda del norte de Africa, ya sea residente en Marruecos o en Melilla,

\footnotetext{
' En 1986, en el «Laboratoire de Lexicologie et Textes Politiques» de St. Cloud (París) se constituyeron varios equipos de trabajo para el estudio de la prensa contemporánea, bajo el tema general «Analyse linguistique de l'exclusion et de l'inclusion dans les discours nationaliste en Espagne (Etudes lexicometriques sur ordinateur).» El equipo del que formo parte se centra en el estudio de los articulos de información y editoriales publicados en la prensa con motivo de los conflictos surgidos en Melilla a raiz de la aplicación de la Ley de Extranjeria. Los resultados de estas investigaciones serán publicados, próximamente, en una obra conjunta promovida por el Centro de St. Cloud. El estudio que ahora presentamos, aunque se centra en la prensa de la misma época, difiere de la investigación conjunta tanto en sus objetivos como en el corpus y metodologia.
} 
encontramos como muestra de ese confusionismo el empleo de inmigrantes árabes para designar a los marroquíes, como hemos podido detectar en la prensa actual en un artículo titulado: "Esclavos del siglo XX en Almería» (Diario 16, 27, III, 89, pág. 10). En él se afirma:

"Unos mil inmigrantes árabes clandestinos trabajan ilegalmente [...] en Almería. Los árabes -la mayoria marroquies - llegan desesperados hasta el vergel plastificado.» (En todos los textos si no se indica lo contrario, el subrayado es nuestro).

La meżcla de criterios étnicos, religiosos y culturales a la hora de elegir designaciones también la podemos apreciar en el siguiente texto de un artículo publicado en el periódico Melilla Hoy (13-II-86, pág. 3).

«No hace falta pasar muchos dias en Melilla para notar que alli conviven dos comunidades perfectamente diferenciadas por los usos y costumbres de la ciudad. La europea y la musulmana. La «mora» en el lenguaje común de los Melillenses.»

Más palpable es el "mare magnum» en la pluralidad de unidades lingüísticas designativas empleadas para referirse a unos mismos sujetos, como apreciamos en los siguientes extractos de un artículo aparecido en la revista Cambio 16 (enero 1986) a raíz de los conflictos surgidos en Melilla con motivo de la aplicación de la Ley de Extranjería. Dice así:

"Los Gobiernos de Marruecos y España temen un incremento del radicalismo musulmán en Ceuta y Melilla tras la manifestación celebrada el 23 de noviembre pasado en esta última plaza, que congregó a siete mil árabes para protestar contra la Ley de Extranjería española.

La aparición de panfletos llamando a la población musulmana a la lucha armada [...].

El Gobierno de Madrid [...] sabe que en unas elecciones en que la población de origen marroqui tuviera el derecho al voto, España perdería el control de todas las instituciones políticas [...].

El sábado 23 de noviembre, alrededor de siete mil musulmanes, algo menos de un tercio de la población de origen árabe residente en la ciudad de Melilla [...]

La manifestación de la comunidad musulmana fue algo más que un acto 
simbólico. En la convocatoria, la población árabe aparecía por primera vez unida.

E] propósito de la manifestación, la petición por parte de la comunidad árabe de la supresión de la Ley de Extranjería y la concesión del Documento Nacional de Identidad a la población musulmana integrada por cerca de 27.000 personas [...]

Pero no es sólo el Gobierno de Madrid quien teme a los musulmanes melillenses [...] (Cambio 16, $\mathrm{n},{ }^{\circ} 736$, enero 1986)

A esta riqueza de unidades designativas para unos mismos sujetos podemos añadir la diversidad de valores en ciertos calificativos como moro, bereber, etc., aparecidos en textos como el siguiente:

"Aomar Mohamed Dudú. El lider "moro» que surgió del PSOE [...] el economista que lleva la bandera de la media luna en el pleito entre "moros" y "cristianos» en la plaza de soberanía española de Melilla [...] Nacido en Melilla, de padres "moros» y Dudú se considera un bereber y no un marroqui.

La manifestación musulmana del pasado 23 de noviembre es, según Mohamed Dudú, el primer signo de que la paciencia de los «moros» se ha agotado [...] (Cambio 16, n. ${ }^{\circ} 736$, enero 1986).

El trabajo que acometemos tiene un doble objetivo:

a) descifrar el complejo entramado lingüistico-ideológico que subyace al empleo de determinadas unidades lingüísticas designativas para referirse a unos mismos sujetos políticos en un contexto determinado.

b) perfilar el contenido semántico de unidades léxicas como árabe, moro y musulmán, señalando algunos de sus valores sémicos actuales.

\section{la Designación en el Discurso Polf́tico}

Existe una profusión terminológica —denotación, designación, referencia, significación, sentido, significado- provocada por un deseo de perfeccionamiento en el análisis semántico llevado a cabo por autores, como Frege, Stuart Mill, Coseriu, Benveniste, etc., que reconocen lo inútil que resulta 
hablar de sentido o significación en abstracto, es decir, en cuanto relaciones entre las unidades en un sistema lingüístico sin tener en cuenta los «intérpretes» o «intenciones de significación» según Huasserl, en suma, las relaciones del lenguaje con el mundo extralingüístico.

Partiendo de esta premisa Frege distingue entre sentido («sint») y denotación («Bodeutung») en traducción inglesa referencia. Por su parte Charles Morris recalca la dicotomía denotatum / designatum y Carnap la de extensión / intensión o comprehensión que equivaldrá, en la terminología de Stuart Mill, a denotación y connotación respectivamente.

No debemos olvidar la advertencia de J. Lyons ${ }^{2}$ "ciertos filósofos utilizan el término "sentido" para lo que otros utilizarían simplemente significado o, más estrictamente acaso, significado cognoscitivo o descriptivo. De ahi que la distinción entre referencia y sentido se formule a veces entre referencia y significado (...) también se identifica con la distinción de Mill entre denotación y connotación». Lyons establece la distinción entre referencia, denotación y sentido ${ }^{3}$.

E. Coseriu ${ }^{4}$ resalta la necesidad de distinguir entre designación, sentido y significado aunque también emplee el término significación.

La designación o hecho de que un signo remita a un objeto o proceso de la realidad extralingüistica queda definida por Coseriu ${ }^{5}$ como «la referencia a lo extralingüistico (que, por supuesto, se da a través del significado), a lo extralingüístico mismo (en cuanto "designado" ya sea como estado de cosas o como contenido de pensamiento (estado de cosas pensado)». Las expresiones pueden diferir en sentido y tener la misma referencia ya que el mismo «objeto» puede ser designado con distintos signos.

Por consiguiente, además de la significación, caracterizada por Coseriu como conceptual y como hecho de «lengua», diferencia este lingüista la designación concreta como material y hecho de udiscurso». Consecuentemente las relaciones de designación concreta son inconstantes (variables) mientras que las relaciones de significación son constantes.

En esta misma línea se expresa E. Benveniste ${ }^{6}$ cuando delimita la noción de "sentido» en tanto que difiere de la «designación». Dice así «Este «sentido" es implícito, inherente al sistema lingüistico y a sus partes. Pero al mismo tiempo el lenguaje hace referencia al mundo de los objetos, a la vez globalmente, en sus enunciados completos, bajo forma de frases, que se relacionan con situaciones concretas y específicas, y bajo forma de unidades

2 J. Lyons., Semántica. Barcelona, Editorial Teide, 1980, págs. 188-189.

Op. cit., pág. 166 y ss.

4 Coseriu, E., Gramática, Semántica, Universales. Madrid, Gredos, 1978, pág. 135.

'Op. cil., pág. 135

"Benveniste, E., Problemas de Lingüistica General. Vol. I. Siglo veintiuno editores, 4." edición, 1974, pág. 127. 
inferiores concernientes a "objetos» generales o particulares, tomados en la experiencia o forjados por la convención lingüística. Cada enunciado y cada término de él tiene así un referendo, cuyo conocimiento es implicado por el uso nativo de la lengua.» Es lo que E. Benveniste denomina universo del discurso.

Es evidente que nuestro objeto de estudio pertenece al ámbito de la función referencial, es decir, a la designación.

Ahora bien, la diferenciación significación / designación queda incompleta a la hora del análisis del discurso político en cuanto uso lingüistico determinado por actitudes e ideologías políticas en el que se presentan valores y matices especiales en la palabras, en suma en la designación «sociopolitica».

En efecto, como afirma E. Coseriu» son «valores asociados al significado, no matices del significado: corresponden a la evocación, al modo de presentar las cosas por medio de las palabras, no a la significación y designación simplemente. "Consecuentemente, Coseriu destaca la necesidad de tener en cuenta otra función del lenguaje ${ }^{8}$ "lo que L. Weisgerber llama "efectividad» del lenguaje en la comunidad lingüistica, en la vida pública y en el trato social, como apreciación de las cosas evocada y reflejada por las palabras, como expresión (indirecta) de actitudes frente a cosas e instituciones, a ideas, personas y grupos, o sea, precisamente, como manifestación de creencias, sentires e ideologías.» De aquí la importancia de los aspectos relacionados con los interlocutores (sujeto agente y paciente o receptor), las causas, los modos y los efectos («efectividad») de la designación.

Estamos ante la designación como acto o actitud del sujeto hablante ante los «objetos» a los que se refiere, en suma, ante la designación en el discurso entendido este último como proceso (no producto) aprehendido en las condiciones de producción y en la totalidad de sus mecanismos enunciativos, pues, como afirma E. Benveniste ${ }^{9}$ «la referencia es parte integrante de la enunciación's. Efectivamente, de acuerdo con Lyons la referencia, en cuanto relación que existe entre una expresión y lo que esta expresión representa en las ocasiones concretas en que se enuncia, «es una noción dependiente de la enunciación ya que si admitimos que una expresión tiene referencia, admitimos que se ha enunciado con una cierta intención comunicativa y en un contexto apropiado ${ }^{10}$. Si bien el sentido y la denotación se establecen independientemente de las ocasiones concretas de enunciación,

«Lenguaje y Politica» en El Lenguaje Politico (colectiva). Fundación Friedrich Ebert. Instituto de Cooperación Iberoamericana, 1987. págs. 9-31. pág. 13.

" «Lenguaje y Politica» pág. 14.

- Problemas de Lingǘstica General. V. II. Siglo veintiuno editores, 1977, pág. 85.

${ }^{10}$ Op. cit.pág. 172. 
la referencia es válida para las expresiones en un contexto, no para los lexemas como tales.

El conocimiento de la referencia es imprescindible en todo análisis del discurso ya que, en palabras de E. Benveniste ${ }^{11}$ "Quienes se comunican tienen precisamente en común determinada referencia de situación, a falta de la cual la comunicación como tal no se opera, por ser inteligible el "sentido» pero permanecer desconocida la "referencia».

La referencia de situación y las condiciones de producción del discurso que ahora nos ocupa podemos deducirla, en parte, del análisis del contexto político-social que realizamos más adelante.

\section{CORPUS Y METODOLOGIA}

La forma más ampliamente reconocida de expresar cualquier intencionalidad ideológica en el discurso es, probablemente, la elección del léxico que se va a emplear. En efecto, es evidente la importancia discursiva de la manera de designar, de describir y de calificar a las personas implicadas en los acontecimientos.

Partiendo de la necesidad del estudio de las expresiones en contexto, es decir, la referencia según Lyons, no analizaremos los lexemas como tales. Por el contrario, una vez aceptado el postulado de Lyons ${ }^{12}$ de que "desde el punto de vista gramatical, cabe reconocer tres grandes tipos de expresiones con referencia definida singular en inglés [y en castellano]: a) frases nominales definidas, b) nombres propios y c) pronombres personales", nuestro estudio se limitará al primer caso, aunque, en ocasiones, se trate de nombres comunes o grupos nominales saturados, es decir, formalmente constituidos por artículo, en su empleo referencial y teniendo en cuenta el carácter designacional-denominativo de los nombres.

En consecuencia, nuestro estudio va a ceñirse a las unidades lingüisticas designativas constituidas sobre la base de una unidad léxica pivote.

El punto de anclaje en nuestro trabajo es un corpus de prensa contemporánea constituido por escritos publicados en la prensa diaria en torno a los conflictos surgidos, en Ceuta y Melilla, con motivo de la aplicación de la llamada Ley de Extranjería en estas dos ciudades norteafricanas, en las que viven varios miles de personas de origen marroqui, aunque algunas asentadas desde generaciones.

El corpus es abierto, es decir, heterogéneo en cuanto a la tipología de

"Problemas.... V.I. . pág. 129.

${ }^{12}$ Op. cit., pág. 171. 
escritos sobre los que está constituido, ya que se trata de artículos de opinión, entrevistas, cartas al director, etc., con exclusión expresa de los editoriales y escritos de información ${ }^{13}$.

Debemos destacar que el hecho de haber escogido esta heterogeneidad de escritos implica aspectos positivos y negativos. Positivos en cuanto enriquece el corpus, especialmente cuando se trata del periódico Melilla Hoy en el que se publican escritos tanto de «musulmanes" como de "cristianos». En el otro extremo, puede producirse un empobrecimiento cuantitativo en periódicos que no acostumbran a publicar este tipo de escritos y cualitativo al no poderse apreciar, siempre, la postura «oficial» de cada diario.

La homogeneidad temporal del corpus queda asegurada con la fijación del período de tiempo comprendido en un año. Se inicia el día 23 de noviembre de 1985, en que se lleva a cabo la primera gran manifestación en Melilla, y se prolonga hasta el 22 de noviembre de 1986, fecha en que se celebra la última manifestación protagonizada por los mismos agentes sociopolíticos.

Los emisores aparecen plasmados en los diarios o periódicos ideológicamente más representativos del amplio espectro ideológico de la prensa nacional y local en la época. Estos son: El Pais, Diario 16, El Alcázar y Melilla Hoy, siendo este último totalmente local. Las designaciones y la consecuente ideología subyacente de los «musulmanes» ha quedado recogida en los periódicos de Melilla Hoy y El Sur, periódicos que admiten escritos de las dos comunidades y que, por tanto, los tomamos como medio de expresión de la "comunidad musulmana»".

Queda pendiente un estudio pormenorizado de la postura del Gobierno y de los partidos políticos, especialmente de Melilla, en el empleo de las designaciones. Únicamente el Partido Comunista de España, en concreto Santiago Carrillo y Julio Anguita, así como el sindicato Comisiones Obreras, apoyaron las movilizaciones y reivindicaciones de los mulsumanes en Melilla durante este año de 1985-86.

Si bien, como ya hemos indicado, este corpus es el punto de partida y base esencial en nuestro trabajo, no obstante, también lo extenderemos a la prensa más reciente en el tiempo y a otros diarios como $E l$ Independiente (1989), A B C (1989), etc., como principio comparativo, con objeto de obtener un análisis más completo y profundo del significado de ciertos tér-

${ }^{13}$ Excluimos de nuestro trabajo estos artículos de prensa por ser la base del corpus de la investigación conjunta ya mencionada en nota 1 .

${ }_{14}$ A partir de ahora utilizaremos estas unidades léxicas (sin entrecomillado) para referirnos a la comunidad de origen marroqui arraigada en Ceuta y Melilla desde generaciones o recientemente inmigrada. El hecho de decidirnos por esta terminología se basa, únicamente, en su mayor frecuencia de uso en la época. 
minos como moro y árabe en la constitución de algunas unidades lingüísticas designativas.

Por último, nos interesa destacar que en esta andadura es obligada la referencia a las definiciones recogidas en algunos de los principales diccionarios de la lengua española.

Dado que nuestro objeto de estudio se centra en las unidades lingüísticas designativas y sus valores o sentidos en el discurso político-social, el método que aplicaremos es básicamente lexicológico, pero teniendo en cuenta que estas unidades están inmersas en el discurso.

Si seguimos la distinción establecida por E. Coseriu, para el análisis del contenido lingüistico, entre designación, significado y sentido, este estudio no se limitará al análisis del significado de las unidades lingüísticas designativas sino que desembocará en el sentido, es decir, en «el contenido lingüístico especial que se expresa en un texto determinado por medio del significado y de la designación, y más allá del significado y la designación»". ${ }^{15}$

Del estudio sintagmático y paradigmático de las unidades lingüísticas deduciremos no sólo los valores polisémicos sino también hiperonímicos e hiponímicos.

En suma, con el estudio de las unidades lingüísticas designativas en el discurso buscamos descubrir las intenciones políticas y, más concretamente, la ideología subyacente en los diversos empleos de los distintos emisores y, en cierto modo, en las diferentes etapas del conflicto causante de los escritos publicados en la prensa de esa época.

\section{CONTEXTO POLÍTICO-SOCIAL ${ }^{16}$}

El intento de aplicación, en las ciudades de Ceuta y Melilla, de la llamada Ley de Extranjería (Ley Orgánica 7/1985 de 1 de julio sobre los Derechos y Libertades de los Extranjeros en España) provocó el estallido de una serie de sentimientos, quizá ya latentes, que se reflejaron, especialmente en Melilla, en una serie de protestas y manfestaciones a lo largo de todo un año (noviembre 1985-noviembre 1986) y la confrontación entre las dos comunidades más numerosas de Melilla: la comunidad «musulmana» y la "cristiana».

El origen de esta situación conflictiva puede ubicarse en la discriminación padecida por los musulmanes de ambas ciudades norteafricanas no sólo

15 Op. cit., pág. 136.

16 Advertimos que es un extracto de lo redactado en 1988 y entregado a los demás miembros del equipo de la investigación conjunta de St. Cloud. 
en el terreno legal sino también en aspectos político-sociales de la vida, rayando, a veces, en racismo. Dicha discriminación fue reconocida, posteriormente y públicamente, por el alcalde de Melilla y el delegado del Gobierno en Melilla e incluso por otras autoridades del gobierno, como el Director General de Política Interior y el Ministerio del Interior.

En el aspecto legal es notoria la existencia, en nuestro ordenamiento jurídico, de una discriminación de los marroquíes residentes en estas dos ciudades con respecto a otros pueblos. Ya en el Código Civil se priva a los marroquies de los beneficios concedidos a oriundos de otros paises en lo que respecta a la adquisición de la nacionalidad. En efecto, si la posibilidad de adquirir la nacionalidad española además de por matrimonio, está contemplada, normalmente, tras la residencia continuada de diez años, este período se reduce a dos años para los de origen de "países iberoamericanos, Andorra, Filipinas, Guinea Ecuatorial o Portugal y sefardies». Como se observa, no se alude a los marroquies asentados en Ceuta y Melilla. Esta discriminación, junto con otras, como por ejemplo la discriminación en el trabajo (art. 23 de la Ley de Extranjería) también la recoge la Ley. En suma, esta ley trata como «extranjeros» a la población de origen morroquí asentada e incluso nacida en Ceuta y Melilla.

Los musulmanes de Melilla forman un colectivo heterogéneo que integra a familias que llevan hasta tres y más generaciones asentadas en esta ciudad junto con inmigrantes llegados en las últimas décadas.

Los datos que se ofrecen con respecto a esta población son muy poco precisos. En ocasiones se afirma que de una población de 72.000 habitantes, son 27.000 los marroquies asentados en Melilla, mientras que, otras veces, se registra que la población marroquí en estas ciudades representa la tercera parte de la población local, siendo unos 15.000 en Ceuta y 17.000 en Melilla.

La situación legal de estos marroquíes, en 1985, es muy irregular, pudiendo clasificarlos en tres grupos:

1. Los que tenían la nacionalidad española. Se calcula que eran únicamente 3.000, aunque también se barajan las cifras de 7.000 y 5.000 .

2. Los que estaban en posesión de la tarjeta de estadistica, documento de valor nulo jurídicamente, con el que no podían ni adquirir una vivienda, ni viajar a la Península, etc. Los marroquíes que la poseían era sólo a efectos de censo.

3. Los demás marroquies estaban indocumentados ante la legislación española, pues únicamente poseían la anecua o documento nacional marroquí. Hecho resultante de la no necesidad de presentación de un pasaporte para atravesar la frontera en Melilla, aunque si en Ceuta. 
Consequencia directa de esta situación es la discriminación político-social de los marroquíes de estas ciudades. No gozaban de ninguna participación en la vida política, pues no tenían derecho al voto ni podían constituirse en partido político, aunque ya en Febrero de 1986 se reconoció el denominado "Partido de los Demócratas de Melilla» cuyo presidente era Aomar Mohamedi Dudú.

Socialmente, la situación de los marroquíes difería mucho de la de los españoles de Melilla. Gran parte de estos marroquíes había cruzado la frontera en busca de trabajo, especialmente en los años setenta y ochenta aunque el inicio de este trasvase de población se cifra en los años cincuenta. Constituyeron una mano de obra barata, cuyo nivel y calidad de vida se plasmaba en el hacinamiento y estado deplorable de los barrios donde vivían, como por ejemplo, el barrio de la Cañada de la Muerte, recientemente dotado de luz y donde, en palabras del alcalde, «las aguas residuales van a flor de tierra». Como anécdota se puede aportar que estos marroquíes no tenían un cementerio y debían trasladar a los difuntos a tierras marroquíes ${ }^{17}$.

Una aplicación estricta de la Ley supondría el otorgamiento de un permiso de residencia a todos cuantos se acogieran a la ley en el plazo que expiraba el 31 de enero de 1986 - hecho dificil para todos aquellos que carecían de documentación-y la posibilidad de acceder a la nacionalidad española a los diez años de obtenida la residencia. En el caso contrario, serían considerados extranjeros, implicando su expulsión del país.

Todas estas circunstancias provocaron un período de conflictos en estas dos ciudades, especialmente en Melilla, donde los marroquies iniciaron sus protestas y proclamaron sus reivindicaciones político-sociales, apoyándose especialmente en la reclamación de la NO aplicación de la Ley de Extranjería pues, de lo contrario, les convertiría, según sus palabras, en "extranjeros en su propia tierra». Recordemos que los musulmanes melillenses se consideraban en esta época —que no un año más tarde- como luego veremos, melillenses y no extranjeros.

Por su parte, la población cristiana o no marroquí expresó su temor de que se llegase a legalizar una situación irregular con la concesión masiva de nacionalidades a los musulmanes o marroquíes en Melilla, hecho que redundaría en un desequilibrio de las comunidades y su repercusión en todos los órdenes de la vida político-social. Todo ello dio lugar, en Melilla, a un largo año de tensiones y enfrentamientos, considerados por algunos dirigentes políticos españoles como actitud que obedecía a una maniobra política del rey Hassan II con relación a sus reivindicaciones sobre estas dos ciudades españolas.

Aunque en un principio la comunidad musulmana estaba dividida, pues

17 Una visión más pormenorizada de la situación en estos barrios puede obtenerse del libro de R. Crespo: Moros y Cristianos. Editorial Andalucía, 1985. 
formaban diferentes asociaciones con diversos dirigentes, sin embargo, en el mes de octubre de 1985, comenzaron a constituirse los comités de barrios que, junto con la asociación Comunidad Musulmana y la asociación cultural Terra Omnium, organizaron al denominado "colectivo musulmán», cuyo dirigente, Aomar Mohamedi Dudú, fue nombrado por elección en Asamblea.

Las movilizaciones se inician el día 23 de noviembre, fecha en que se celebró la primera manifestación de musulmanes contra la Ley de Extranjería. Como réplica «nacional», el día 6 de diciembre, se celebra una contramanifestación convocada por todos los partidos politicos de Melilla, en la que participaron los melillenses a favor de la Ley de Extranjería y en apoyo del Delegado del Gobierno.

La conflictividad desatada entre las dos comunidades en Melilla se prolongó durante un año, cerrándose el ciclo con la manifestación del día 22 de noviembre de 1986, cuyas características fueron muy distintas a las de la primera manifestación celebrada un año antes por los mismos sujetos políticos.

Ante la imposibilidad, por razones de espacio, de una exposición más pormenorizada de los acontecimientos, describiremos, sucintamente, la postura de los sujetos implicados en ellos.

Sobresale el descontento existente entre los musulmanes y que se refleja en acontecimientos como la celebración, por primera vez en la historia, de manifestaciones de mujeres musulmanas contra la Ley, el cierre de comercios regentados por musulmanes, la protesta contra el Ayuntamiento por la demora en la tramitación de la documentación necesitada para legalizar la situación de los musulmanes, etc.

La comunidad cristiana, después de la gran manifestación del 6 de diciembre, no parece organizada y responde con altercados de mayor o menor consideración, esencialmente, en apoyo de la policía nacional y de las opiniones que propugnaban la aplicación estricta de la Ley, así como solicitando la dimisión del Delegado del Gobierno, hecho que finalmente se produjo el 29 de agosto, contrarrestando con la aceptación, por parte de Mohamedi Dudú, del cargo de asesor del Ministerio del Interior para estudiar los problemas sociales, religiosos y económicos del colectivo de los musulmanes del cual era representante.

El Gobierno proclama su deseo de que se lleve a cabo la integración de los musulmanes en la sociedad española. En febrero de 1986, representantes de los Ministerios de Interior y Justicia, con la intermediación de la oficina del Defensor del Pueblo, y representantes de las comunidades musulmanas de ambas ciudades firman unos acuerdos, entre los cuales destaca la creación de una Comisión Mixta para dar solución a los conflictos presentados por la aplicación de la Ley de Extranjería. Posteriormente, en octubre de 1986, en una reunión de esta comisión mixta, el Ministerio del Interior anuncia estudiar la posibilidad de dotar de documento nacional de identidad pro- 
visional a los musulmanes de Ceuta y Melilla que estuviesen tramitando la solicitud de nacionalidad española y una documentación especial de residencia, renovable a los diez años, en los casos en que no sea solicitada la nacionalidad o no cumplan los requisitos necesarios.

El 1 de abril entra en vigor, en toda España, la ley de Extranjería ya aplazada por tres veces. Transcurridos tres años desde el inicio de estos conflictos en Melilla, se publican los siguientes datos, ofrecidos por el Grupo de Iniciativas Territoriales, sociedad contratada por el Ministerio del Interior para coordinar actuaciones en Melilla, sobre la situación de los 20.000 musulmanes residentes en Melilla:

- Unos 3.500 musulmanes han regularizado su situación y disponen de D.N.I.

- Otros 5.000 tienen ya finalizados los trámites de acceso a la nacionalidad española.

- Y otros 1.500 disponen de carnet de identidad provisional.

En todo este conflicto cabe destacar la evolución sufrida en su enfoque dentro de la comunidad musulmana. Frente a la españolidad propugnada por los musulmanes en su inicio, resalta la manifestación celebrada el 26 de abril para protestar por el racismo y reivindicar su cultura, música, religión y lengua, así como la radicalización de su postura favoreciendo las tesis promarroquíes. Resultado final de esta evolución es el comunicado realizado en la Asamblea del 8 de noviembre de 1986, en el que se declara el carácter árabe y musulmán de la ciudad de Melilla y se proclama la solidaridad panárabe. Uno de los «slogan» más frecuentemente repetido en la última manifestación, celebrada el 22 de noviembre de 1986, reza así: «Melilla magrebí, árabe y musulmana.»

\section{UNIDADES LINGUÚSTICAS DESIGNATIVAS}

Pasamos a examinar las unidades lingüisticas designativas que corresponden a las dos comunidades (musulmana y cristiana) mayoritarias en Melilla durante la época que nos compete. Empezaremos por las unidades que "refieren" a la comunidad musulmana, ya que su designación es la de mayor controversia en este conflicto.

\section{Unidades constituidas con el término musulmán}

En el conflicto surgido en Melilla a raíz de la aplicación de la Ley de Extranjería predomina, notoriamente, la utilización de las unidades lin- 
güisticas designativas constituidas con el término musulmán para designar a esta parte de la población de Melilla originaria de Marruecos aunque, a veces, asentada en esta ciudad desde tiempos lejanos.

\subsection{Aclaración sobre el término musulmán}

Debemos iniciar nuestro estudio con unas breves aclaraciones y precisiones con respecto al término musulmán, ya que va a ser el núcleo nominal de muchos sintagmas o el calificativo de gran parte de las designaciones que entran en nuestro análisis.

Si recurrimos a los diccionarios de la lengua española para comprobar las definiciones del término, observamos que existe un claro entronque con la religión mahometana o islámica. Así en el Diccionario de la Real Academia Española ${ }^{18}$, la entrada musulmán remite a mahometano «Que profesa la secta de Mahoma». De igual manera, en el Diccionario de Uso del Español de M. $^{a}$ Moliner $^{19}$, figura "se aplica a los adeptos a la religión de Mahoma y a sus cosas"s.

En este mismo sentido el término está empleado por los diferentes historiadores. Así por ejemplo, Lévi-Provençal, en su obra España Musulmana $^{20}$, bajo este calificativo describe la invasión y expansión árabe con la dinastía omeya, el califato de Córdoba, los reinos de taifas y las invasiones de almohades y almorávides. Con gran precisión encontramos en $\mathbf{R}$. Mantran ${ }^{21}$ la diferenciación terminológica en la sociedad que en un principio fue llamada árabe, después arabo-musulmana y finalmente musulmana, pues ya durante el imperio de los abbāsies existian diversas etnias diferentes de la árabe, promotora esta última de la expansión e imperio, pero una única religión, la musulmana o islámica.

No obstante, debemos destacar lo que se recoge en el diccionario de Corominas ${ }^{22}$ con relación a esta entrada léxica: "Musulmán es palabra de introducción moderna y de carácter culto; en francés y en inglés es más antigua, en este último idioma se documenta Musulmán desde 1563. Esporádicamente se habia empleado en castellano la variante mosolimán [...]. Lo popular, sin embargo, fue siempre decir moro o (al)árabe, con sentido

18 Diccionario de la Real Academia Española. Vigésima edición, Madrid, 1984.

19 Moliner, M.", Diccionario de Uso del Español. Madrid, Gredos, 1980 (reimpresión).

20 E. Lévi-Provençal, España Musulmana, Madrid. Espasa Calpe, 1982.

21 Robert Mantran, La Expansión Musulmana (siglos v1 al xl), Barcelona, Editorial Labor, 1982.

2: Joan Corominas, Diccionario Crítico Etimológico de la Lengua Castellana, Madrid, Gredos, 1974 (reimpresión). 
religioso y prescindiendo de la razan. El término musulmán no aparece ni en el Diccionario de Autoridades ni el de Covarrubias ${ }^{23}$.

Ahora bien, si nos centramos en las designaciones que hemos hallado en la época que ahora nos ocupa, observamos dos hechos: a) la preferencia de uso de unidades lingüísticas constituidas con este término musulmán y b) los valores peculiares y concretos aplicados al mismo.

El propio Aomar Mohamedi Dudú, presidente de la organización «Terra Omnium» y dirigente del "colectivo musulmán", ya desde el comienzo de los acontecimientos en Melilla puntualiza: «Debo declarar que los términos "cristiano" y "musulmán" han de entenderse en sentido político, no estrictamente religioso.» (Melilla Hoy, 11-XI-85, p. 6).

El empleo de ambos términos en el sentido político para diferenciar las dos comunidades mayoritarias de la ciudad de Melilla fue recalcado, de nuevo, por Dudú en la manifestación habida el 26 de abril de 1986. No obstante, otro miembro de la comunidad musulmana en Melilla, Mohamed Ahmed Moh, representante de la Agrupación de la Comunidad Musulmana de Melilla, no parece estar de acuerdo con el empleo político de.musulmán cuando afirma: «El término musulmán es un término religioso y me parece una barbaridad mezclar la política con la religión, y la religión con la política [...]» (Melilla Hoy, 11-VI-86, p. 7). Estas declaraciones forman parte de la rivalidad existente entre ciertas asociaciones musulmanas, como se plasma en la contestación de Abderramán Mohamed Hamed a las declaraciones anteriores:

"Quisiera recordarle que Aomar en ningún momento ha dicho que el problema es religioso, cuando se refiere a cristianos lo dice siempre en términos políticos y nunca religiosos porque es la única manera de la que se puede diferenciar un colectivo, [...]" (Melilla Hoy, 12-VI-86, p. 5).

En cualquier caso, justifica el empleo de un término religioso, musulmán, con ese carácter político que manifiesta la lucha reivindicativa del momento, remontándose a principios religiosos cuando dice:

"Le hago recordar [a Moh] que el significado de musulmán es obediencia, obediencia a los mandatos de Dios y este dijo, maldito aquel que no lucha contra 1984.

${ }^{23}$ Real Academia Española, Diccionario de Autoridades, Edición facsímil, Madrid, Gredos,

Sebastián de Covarrubias, Tesoro de la Lengua Castellana o Española, Edición de Martín de Riquer de la Real Academia Española. Barcelona, Editorial Alta Fulla, 1987. 
la represion, contra la discriminación, en resumen, maldito todo aquel que no luche por los derechos fundamentales del hombre, maldito aquel que traiciona a su pueblo (al pueblo de Umma, al pueblo Muslim).»

Sin embargo, el empleo del término musulmán con pleno valor religioso parece recuperarse poco a poco en el transcurso del tiempo y según la evolución de los acontecimientos. En efecto, ya en la manifestación celebrada en abril de 1986 se detecta su finalidad: reivindicar la cultura árabe y la religión musulmana.

Esta reivindicación vuelve a repetirse con mayor énfasis e hincapié en la Asamblea de la comunidad musulmana anterior a la última manifestación estudiada por nosotros, es decir, la del 22 de noviembre de 1986. En esta asamblea se pide la enseñanza del árabe y de la religión musulmana y se defiende el "carácter árabe y musulmán». En la propia manifestación se proclama el "carácter árabe, musulmán y magregi» de Melilla.

En los artículos publicados principalmente al principio de los acontecimientos y firmados por personas no musulmanas encontraremos un rechazo al empleo del término musulmán para designar a ese sector de la población melillense por diferentes razones. En este sentido se encuentran las declaraciones del Vicario Episcopal de Melilla, don Lorenzo Orellana, en diciembre de 1985 (El Sur, 12-XII-85).

«Melilla vive por estos dias una fuerte tensión interior magnificada por los medios de comunicación social que, entre otras, usan constantemente expresiones como "enfrentamiento entre moros y cristianos" o "reivindicaciones del colectivo musulmán frente al cristiano".

Desde el principio, por radio y prensa local, me he opuesto a que se usen estos términos y he insistido en los puntos siguientes [...] Creo que el problema de Melilla nunca debería plantearse como un choque entre religiones, sino de convivencia entre españoles sean de la religión que sean [..]

En resumen, de lo que se trata es de un problema de justicia, y, por tanto, no es ético el uso de unos términos que distorsionan la realidad.»

En este mismo sentido, aunque incluso con anterioridad, se expresa don Juan Garbín Vereda:

"[...] por eso, cuando se esgrime con harta frecuencia la palabra musulmán para definir una situación determinada, que nada tiene que ver con el concepto de religión que esa palabra tiene hay que decir QUE SE ESTÁ MANIPULANDO o bien TERGIVERSANDO.» (Melilla Hoy, 17-XI-1985, p. 4). 
En junio de 1986, en su "Carta abierta al delegado del gobierno" (Sur, 24-VI-86, p. 20) vuelve a insistir sobre el empleo de la terminología de la que puede deducirse una discriminación por razón de religión:

«Pero lo que a mi me ha extrañado es que usted reitere lo de [comunidad] "integrada fundamentalmente por cristianos y musulmanes". Pues usted sabe que llevo tiempo oponiendome a que nos dividan así [...] y también, porque presiento que tras ese lenguaje de comunidad cristiana frente a musulmana se puede libanizar Melilla. Por lo tanto, le pido a usted [...] que no nos discrimine por razón de la religión.»

Por el contrario, en El Pais, en el editorial de 29 de enero de 1986, se reitera la denominación de melillenses de religión musulmana.

En la misma línea de oposición a esta terminología se encuentran las declaraciones de Zapata, excanciller del Consulado General de España en Nador, quien destaca el peligro que encierra el utilizar este término con el nuevo contenido conceptual:

\begin{abstract}
"Desde hace un cierto tiempo vengo observando en la prensa y en otros medios de difusión, la aparición de un concepto nuevo, al menos para mí, pese a mis 44 años de residencia en Marruecos y es el de población musulmana [...] Lógicamente me lleva a pensar que la aparición de este nuevo concepto en estos días, no tiene otro sentido que el provocar un enfrentamiento al menos dialéctico, con el de cristiana, por las connotaciones radicales de ambas religiones, particularmente sentidas en unas determinadas áreas y pese a lo obsoleto del planteamiento [...] cabria preguntarse si a estas alturas y cuando prácticamente termina el siglo $\mathrm{xX}$, si vamos a rememorar las viejas cruzadas [...]) (Sur, 14XII-85, p. 18).
\end{abstract}

Esta dialéctica musulmanes/cristianos e incluso moros/cristianos, como más adelante estudiaremos, reflejará un enfrentamiento que, para algunos adquiere tintes religiosos, para otros de diferencia racial o étnica y, en la mayor parte de los casos, una discriminación que, en última instancia, resultará esencialmente una diferenciación entre las dos comunidades mayoritarias en Melilla.

\title{
1.2. Los musulmanes
}

En esta época, con esta unidad lingüistica se designa en Melilla a un colectivo heterogéneo compuesto por los excombatientes del Ejército es- 
pañol y sus descendientes, así como por familias enteras de marroquíes ya asentadas en Melilla antes o durante el protectorado, es decir, durante varias generaciones, y también por inmigrantes llegados en las últimas décadas. No existe una total homogeneidad en la designación de este colectivo ya que el primer grupo será destacado y delimitado, como luego veremos, denominándolo de manera diferente según las ideologias.

La designación con la unidad lingüistica los musulmanes, haciendo referencia a la población marroquí inmigrante en Melilla y asentada en mayor o menor grado, es utilizada por la mayoría de los emisores e incluso por los mismos designados; hecho este último que queda corroborado y confirmado con el uso de indicios enunciativos personales como "en nosotros los musulmanes" (Melilla Hoy, 5-IX-1986, pág. 6) en boca de Abderramán Mohamed Hamed.

La excepción a este empleo la protagoniza la derecha, y más concretamente la ultraderecha que preferirá los marroquies por razones diversas que luego examinaremos. Para apoyar algunas de estas razones, remiten al valor hiperonímico de los musulmanes, como se desprende de las siguientes declaraciones de Ismael Medina en El Alcázar (14-II-86, pág. 6).

«El primer gatuperio reside en atribuir a la comunidad musulmana un problema que sólo afecta a los residentes marroquies en los territorios españoles de Ceuta y Melilla. Que pertenezcan a la religión musulmana carece en absoluto de entidad para obtener la nacionalidad [...].

Aunque pueden existir en Ceuta y Melilla musulmanes de otras naciones del Ãfrica islamizada, que dicen los árabes, la llamada comunidad musulmana la componen, en su inmensa mayoría marroquíes que inmigran en diversos periodos [...]. Los términos en que está redactado el acuerdo [...] supone meter en el mismo saco que a los marroquies aposentados en Ceuta y Melilla a todos los musulmanes llegados a España desde cualquier ámbito del mundo islámico: palestinos, polisarios, argelinos, libios, iraquies, iranies,s etc.»

A pesar de la aceptación generalizada de la designación los musulmanes, sin embargo, se puede comprobar que el índice de frecuencia de uso es muy bajo con respecto a otras unidades como comunidad musulmana, población musulmana, colectivo musulmán e, incluso queda un poco relegado su empleo, prefiriéndose otras unidades lingüisticas designativas más precisas para determinados momentos y circunstancias como son los musulmanes de Melilla, los musulmanes melillenses, etc.

\subsection{Los musulmanes en/de Melilla. Los musulmanes melillenses. Los españoles musulmanes}

Estas designaciones son utilizadas por diarios como El País, Diario 16 y Melilla Hoy y, especialmente, por los musulmanes en sus manifestaciones 
y escritos dè los primeros meses del conflicto en los que se defendía su no extranjería e, incluso, su españolidad.

En efecto, Dudú retoma la identificación de melillense con español inculcada y defendida por los habitantes de Melilla, identificación cuyo máximo exponente visible y notable fue la contramanifestación del día 8 de diciembre en favor de la Ley de Extranjería. Así Dudú en su artículo «La ley de la extranjería o la legalización de la esclavitud" (Melilla Hoy 11-XII1985, pág. 6) dice:

«El pasado día 23 de noviembre los musulmanes de Melilla protagonizamos la manifestación más concurrida que se recordaba en la ciudad [...].

y más adelante, cuando informa sobre la asamblea preparatoria de esta manifestación, se expresa así

«No sólo intentó (el Delegado del Gobierno) truncar una asamblea de los musulmanes melillenses [...].»

Asimismo, en los comunicados del colectivo musulmán publicados en los primeros meses del conflicto también aparece la designación musulmanes melillenses.

La defensa de la no extranjería de la población musulmana queda explicitada en declaraciones del propio Dudú en diciembre de 1985:

«Los musulmanes [...] no aceptamos desde ningún punto de vista la Ley de Extranjeria. Porque ni somos ni nos consideraremos nunca extranjeros en nuestra tierra. Somos melillenses (por nacimiento unos; por largos años de residencia, otros) y por tanto (nos sentimos y somos españoles) [...] y como somos y nos sentimos españoles queremos vivir en Melilla como tales. Y queremos la nacionalidad española para todos los musulmanes de Melilla [...]. La manifestación musulmana del pasado día 24 contra la Ley de Extranjería fue un testimonio ordenado y clamoroso de que el musulmán melillense se siente español y quiere que se le reconozca como tal, porque quiere tener voz y voto en su tierra.» (Melilla Hoy 11-XII-85, pág. 6).

La defensa de la españolidad de los musulmanes queda aún más patente en el empleo de otra unidad designativa «nuestra condición de españoles 
musulmanes» en boca de Abdeluar Mohamed (Melilla Hoy 20-XII-85, pág. 3) donde el calificativo españoles queda antepuesto.

Esta identificación de musulmán con melillense y con español no parece reconocida espontáneamente por el resto de los melillenses y españoles, como se desprende de unas declaraciones de José González Orell con relación a la manifestación habida el día 6 de diciembre de 1985:

"Hay algo que me preocupa en esta manifestación y es que los tres mil musulmanes melillenses, los tres mil musulmanes españoles, perdón, parece que no están aqui, eso es algo que me preocupa enormemente.) (Melilla Hoy 6-XII85.)

Negaciones más rotundas se encuentran cuanto más se aproximen los emisores hacia la ideología de la derecha y ultraderecha, aunque, como ya dijimos anteriormente, el análisis pormenorizado de la postura de los partidos políticos ante el conflicto queda pospuesto para otra ocasión.

Veamos a continuación unas declaraciones de don Francisco Javier Treviño Ruiz en enero de 1986, como réplica a las publicaciones aparecidas en El Pais:

"[...] y está [el sr. Cebrián] distorsionando la realidad para favorecer a unos señores que ni son españoles ni merecen serlo porque en este tipo de asuntos no basta con que a uno se le reconozca un derecho, como pueda ser la adquisición de la nacionalidad, hay que merecerlo [...] no nos engañemos se sienten marroquies en su mayoría [...] La mayoría no son ni melillenses ni españoles pero tienen la desfachatez suficiente para proclamar lo primero con el ánimo en el futuro de ¡sabe Dios qué!» (Melilla Hoy 20-II-86, p. 16).

Evidentemente, esta postura repercutirá en el empleo de las unidades lingüísticas designativas por este sector ideológico, decantándose por las designaciones constituidas con el término marroqui, como población de origen marroqui, colectivo marroqui, comunidad marroqui, etc., hecho que comprobaremos más adelante (véase apartado 6).

La decidida actitud española de los musulmanes en los primeros meses del conflicto derivará, con el paso del tiempo, hacia una promarroquización. De hecho, si en un principio enarbolaban la bandera de la tierra y del indigenismo en defensa de su españolidad no admitiendo ser considerados "extranjeros en su propia tierra", esta consideración de autóctonos dará la vuelta. Tras propugnar la africanidad de Melilla y el hecho de que fuesen ellos los primeros habitantes de esos territorios pues, según Aomar Dudú, 
la presencia cristiana en la actual Melilla no se remonta a 1942 sino que adquiere consistencia en este siglo "cuando nosotros ya estábamos aquí" (Sur, 22-I-86, p. 29), en noviembre de 1986 se aprueba una moción en la que el colectivo musulmán declara el carácter árabe y musulmán de la ciudad.

\subsection{Comunidad musulmana, población musulmana, colectividad musulmana, colectivo musulmán, pueblo musulmán}

Todas estas unidades designativas son empleadas frecuentemente por la mayoría de los periódicos estudiados, con excepción de El Alcázar, como se ha dicho anteriormente.

Debemos destacar la unidad lingüistica designativa el colectivo musulmán no sólo por el alto índice de frecuencia de uso sino por el valor concedido, especialmente por los propios musulmanes. Será un valor de unidad aglutinadora en la lucha, quizá herencia del apoyo prestado por el sindicato de Comisiones Obreras. Este colectivo musulmán «basándose en estatutos constitucionales crea sus propios representantes" (Abdeluab Mohamel Maanan, Melilla Hoy, 5-XII-85, p. 3) y tiene un "comité coordinador ( $\mathrm{Me}$ lilla Hoy, 20-II-86, p. 16) que emite "comunicados». Este colectivo musulmán «lucha" por sus "reinvindicaciones», como se desprende de los textos analizados en los que estos términos entran en la misma red semántica asociativa y constituyen unidades lingüisticas formadas con el complemento determinante colectivo musulmán. Por ejemplo, en «Desde que se inició la lucha polémica del colectivo musulmán de Melilla por su igualdad, integridad [...]", (Melilla Hoy, 2-XI-86, p. 9) y en "Dentro de nuestro colectivo existen personas cualificadas para seguir reivindicando nuestros derechos, con Aomar o sin Aomar", (Melilla Hoy, 8-XI-86, p. 5). Con este valor también lo emplean autores no musulmanes, principalmente en El Pais (2-II-86).

"Las tensiones que desde hace meses se registran en Melilla debido a las peticiones del colectivo musulmán para legalizar su situación [...]»

Otra muestra la tenemos en,

«abanderar las reivindicaciones del colectivo musulmán» (El Pais, 16-II-86, p. 6).

En suma, por el análisis distribucional de la unidad colectivo musulmán, 
podemos deducir su carácter agente no sólo por su función de sujeto de verbos de acción, sino también como complemento determinante de sustantivos como lucha, reivindicaciones, etc.

En la última época del periodo analizado, esta designación es casi desbancada por el aumento en la frecuencia de uso de la unidad el pueblo musulmán. Su empleo en la primera etapa del conflicto hubiese supuesto una identidad diferenciadora con respecto al pueblo español, hecho que no se correspondería con el primer objetivo de los miembros de la comunidad musulmana de Melilla de ser reconocidos como españoles. Es precisamente a partir del mes de abril de 1986, en la concentración ante el Ayuntamiento, en la que Dudú amenaza con un ayuntamiento o administración local paralela, es entonces cuando se manifiesta públicamente el deseo de una afirmación de la identidad de la comunidad marroquí al asegurar Dudú que el pueblo musulmán es el auténtico pueblo nativo y autóctono de Melilla, y añade para aclarar «nosotros ya vivíamos aquí, cuando a comienzos de 1900 llegaron 20.000 soldados españoles [...] que fue cuando comenzó a hacerse la actual Melilla».

A partir de entonces es notorio el incremento de empleo de la designación el pueblo musulmán, llegando incluso a constituirse el «Comité Coordinador del pueblo musulmán» que podríamos situarlo en el punto opuesto a la «Unión del Pueblo Melillense», partido político seudo-nacionalista existente en Melilla. Todavía en 1990 lo empleará el ex-secretario general de "Terra Omnium» (El País 1-V-90 p. 15).

Cabe señalar que, con el transcurso del tiempo, parece haberse consolidado el empleo de musulmanes, y los sintagmas formados con dicho término, para referirse a la población de origen marroquí con mayor o menor arraigo en Ceuta y Melilla. Así lo corroboran las declaraciones de Manuel Céspedes, Delegado del Gobierno en Melilla (El Pais, 27-III-1990 p. 16) y su registro en distintos artículos de la prensa que, con motivo de la repetición de las elecciones en Melilla (1990), aparecieron en diversos periódicos como Diario 16 (20-II-90, p. 5), El Independiente (20-II-90, p. 3), y revistas como Época (27-II-1990, n..$^{\circ}$ 207), aunque en esta última alterna con marroquí.

Si bien en un determinado momento El Pais utilizó árabes para designar a los originarios de Marruecos pero asentados en Ceuta y Melilla (véase apartado 7), con el tiempo establece una tajante diferenciación entre éstos, a quienes denomina musulmanes, y los inmigrantes procedentes de Marruecos. Así, en Mayo de 1990, con ocasión de la manifestación celebrada en Madrid contra la Ley de Extranjería y el racismo, empleará «musulmanes de Ceuta y Melilla que tienen los papeles (certificado de nacimiento o tarjeta de estadistica) que marca la Ley" (El País 26-III-90, p. 16 y 27-III-90, p. 2 Madrid), mientras que se extiende la denominación de marroquies para aquellos inmigrantes procedentes de Marruecos aunque se encuentren viviendo en España desde los años setenta (El Mundo 28-V-1990, p. 13, 6-VI- 
90, p. 3; Diario 16, $28-\mathrm{V}-90$ p. 13; El Pais, 3-VI-90 y 5-VI-90, p. 20; El Independiente $28-\mathrm{V}-90$ p. 20).

Esta unidad designativa alternará con magrebies (El País 3-VI-90; El Sol, 6-VI-90, p. 8; La Vanguardia, 6-VI-90, p. 36) y ciudadanos o trabajadores norteafricanos (Diario 16, 6-VI-90; El Mundo, 5-VI-90, p. 13; La Vanguardia 6-VI-90, p. 36; $A B C$, «Inmigrantes del Norte de Africa», 28-V-90, p. 26).

\section{Los moros}

El esudio de esta unidad designativa ha sido posible al centrarnos en el corpus que estudiamos y dejar de lado el corpus de la investigación conjunta ${ }^{24}$. En este último prácticamente no aparece esta unidad, indicio manifiesto del recelo de la «oficialidad» a emplearla en este conflicto, a pesar de su uso en el lenguaje cotidiano de la ciudad. La cotidianidad de su empleo ya la pudimos apreciar en un texto recogido en la INTRODUCCIÓN en el que se dice "la [comunidad] "mora" en el lenguaje común de los Melillenses".

Hemos detectado el empleo de la unidad el/los moro(s) tanto en boca de los propios musulmanes como también de la población cristiana. De acuerdo con Carlos Yardoz, enviado especial de El Pais, «Moros y españoles, o marroquíes y españoles, es la terminología empleada generalmente por los cristianos, aceptada incluso, debido a la costumbre, por una mayoría de musulmanes, aunque muchos de ellos hayan nacido, como los llamados españoles en la misma ciudad», (El Pais, 29-VII-86, p. 11).

Prueba del hábito corriente en el uso general de este término son las declaraciones de algunas musulmanas en una entrevista realizada en Melilla (El País, 30-II-86, p. 10) en la que Farida dice, user morita y ser mujer ya es dificil. Ser morita ante los españoles y ser mujer ante los moritos musulmanes». Alí declara, "con la mirada, la mora hace virguerías». Esta generalidad en el empleo en Melilla también se puede apreciar por la parte de los cristianos en frases como «Aquí sólo venís a comer langostinos y a hablar con los moros", reproche que fue proferido a periodistas enviados a Melilla, (El Pais, 29-VI-86, p. 11).

Recurriendo a los diccionarios nos encontramos con la definición bastante restringida del DRAE y de la Enciclopedia del Idioma ${ }^{25}$ en la entrada

24 Nos referimos a la investigación en curso ya citada en la nota 1.

25 Martín Alonso, Enciclopedia del Idioma. Diccionario histórico y moderno de la Lengua Española (siglos XII al XX). Etimológico, tecnológico, regional e hispanoamericano, Madrid, Aguilar, 1982 (2." reimp.). 
Moro «natural de la parte del África septentrional, frontera a España, donde estaba la antigua provincia de Mauritania». En el diccionario de Corominas se explica el origen etimológico del latín MAURUS «habitante de Mauritania».

El diccionario de $\mathrm{M} .{ }^{a}$ Moliner amplía el campo designativo al afirmar "se aplica a los musulmanes que invadieron España y vivieron en ella entre los siglos VII y XV y a sus cosas".

En estos diccionarios se recoge que, por extensión, equivale a Mahometano. En efecto, según el diccionario de Corominas «en España moro se aplicó además a todos los mahometanos, y de ahí pasó a significar "gentil, pagano, no bautizado"». Asimismo, en el diccionario de Autoridades figura la siguiente explicación: «Tómase regularmente por el que sigue la secta de Mahoma.»

El término moro está documentado por primera vez en el siglo XII aunque es, según Corominas «de uso general en todas las épocas» y reconoce que «lo popular, sin embargo, fue siempre decir moro o (al)árabe, con sentido religioso y prescindiendo de razas". Así se constata en numerosos textos históricos y literarios como el Libro de los Estados de D. Juan Manuel, las Cantigas y Crónica General de Alfonso X, el Poema del Mio Cid, la Celestina, etc. Es muy frecuente la expresión trinaria «cristianos, moros y judios».

Realmente en la historia de este constante flujo de poblacion entre España y el Norte de África no queda marcada la diferenciación étnica. Ya desde los comienzos de la España Musulmana aunque originariamente su población la constituían árabes y bereberes, con el tiempo se fusionaron mezclándose con los autóctonos que se islamizaron (mozárabes), olvidando sus origenes árabes y magrebies para, como afirma Lévi-Provença ${ }^{26}$, «fundirse en la masa, cada vez más homogénea, de los andaluces islamizados».

Estamos ante el «factor moro» de la terminología empleada por Américo Castro para reducir los complejisimos conceptos de «lo árabe» y «lo musulmán». Es la casta (¡no raza!) mora, uno de los constituyentes del problema español ${ }^{27}$

Centrándonos ahora en el conflicto provocado por la Ley de Extranjería, observamos, en la mayoria de los periódicos, una escasa circulación de unidades constituidas con el término moro, a no ser para censurar su empleo, debido al bagaje de significaciones o sentidos afectivos con los que se ha ido cargando este término a lo largo de la historia española; escasez que se contrapone al uso, relativamente frecuente, por algunos articulistas en $E l$ Alcázar y en Diario 16. Destacamos, en este caso, la heterogeneidad del

26 Op. cit., pág. 97.

p. [5]

27 Américo Castro, La realidad histórica de España. Sexta edición. México, Porrua, 1975, 
diario Melilla Hoy, pues en él se recogen escritos de las dos comunidades mayoritarias en Melilla.

Curiosamente es el propio Aomar Dudú y su colectivo quienes emplean las designaciones el moro o los moros como si estuviesen proferidas por los cristianos, es decir, como discurso referido, y destacando su carácter despectivo y despreciativo.

Así se observa en las palabras de Dudú durante la asamblea informativa celebrada en la mezquita cultural, el 22 de enero de 1986, en la que culpó al Delegado del Gobierno y al Director General de Política Interior por enviar a Melilla «a los nuevos guerreros del antifaz que trajeron a Melilla a matar moros", (Sur, 30-I-86), refiriéndose a los policías traídos desde la península. En este mismo sentido se expresa un comunicado del colectivo musulmán:

«El camino de la convivencia y de la estabilidad de Melilla será fácil siempre que se rechacen los llamamientos a la discordia a que nos tienen acostumbrados los extremistas políticos que a la menor ocasión predican la cruzada contra el moron, (Melilla Hoy, 20-II-86).

Dudú señala la postura de los políticos y gobernantes contra el colectivo moro, con palabras como «Desde los fascitas hasta Izquierda Unida todos se unen en Melilla contra el moro", (El Pais, 29-VI-86), deseando incluso expulsarlo

«el alcalde ahora va a gastarse con todos los problemas que tenemos los melillenses y en especial los musulmanes, doce millones para promocionar la imagen de la ciudad. Una imagen sin moras, porque al moro hay que echarlo y lo más grave es que lo hacen con nuestro dinero porque nosotros pagamos impuestos", (Melilla Hoy, 27-IV-86, p. 3).

Este deseo de expulsión del moro también se detecta entre los distintos miembros de la comunidad "cristiana» de Melilla. Así se expresa un jubilado:

"Aquí los moros no pintan ni deben pintar nada, que se vayan a su pais. Esta gente se cree que son españoles, pero la verdad es que siguen siendo moros [...] Están pisoteándonos en todos los aspectos y si les dejamos nos comerán), (Melilla Hoy, 23-XI-85, p. 7).

En Diario 16, (24-XI-85, p. 2), Juan de Dios Mellado reconoce que «existe una derecha dura y nacionalista que vería de buen grado la expulsión del "moro». 
Este sentimiento es percibido por el grupo comunista del Congreso el cual pregunta al Gobierno por «las medidas que se propone adoptar la autoridad gubernativa para impedir y reprimir las pintadas racistas y las peticiones a través de algunos medios de comunicación para que sean expulsados los "moros").

Resaltamos el valor semántico del entrecomillado y su función enunciativa de marcar la alteridad pues, como afirma $D$. Maingueneau ${ }^{28}$, el enunciador rechaza asumir la unidad entrecomillada, al mismo tiempo que la enuncia, porque la atribuye a la voz de otro enunciador. El uso del entrecomillado en el término moro se recoge no sólo entre los articulistas (véase también en la INTRODUCCIÓN) sino incluso entre historiadores, como por ejemplo Claude Cohen ${ }^{29}$.

Otros ejemplos de este entrecomillado lo tenemos en los siguientes textos:

"Es uno de los cuatro mil "moros" que se hacinan en barracas de barro y latas del barrio Reina Regente", (Cambio 16, n. ${ }^{\circ} 736$, p. 28).

En el contexto estudiado, el entrecomillado refleja valores que se conceden al empleo de esta unidad designativa, entre otros los que van desde el desprecio racista y degradante hasta la burla.

Así el moro será inculto, como denuncia Hassan en una carta al Director con relación a las declaraciones del Director de Política Interior:

"Esto significa una sola cosa y es que dada la fama que tenemos de incultos se ha querido reir de nosotros. Pero una cosa es que seamos "moros" y otra que seamos tontos», (Melilla Hoy, 6-II-86, p. 6).

Estos moros para algunas personas, especialmente los que comulgan con ideas de derechas, son «masas enajenables que históricamente han soportado la marginación social y el peso de la ignorancia», (Melilla Hoy, 13-IV86, p. 7). Asimismo "son incapaces de integrarse en la sociedad, se automarginan, $[$... $]$ y no son de fiar", (Diario 16, 24-XI-85, p. 2). Hasta el punto de llegar a esta advertencia,

\footnotetext{
2* D. Maingueneau, Approche de l'enunciation en linguistique française. París, Classiques Hachette, 1981. p. 108.

${ }^{29}$ Claude Cahen, El Islam, Siglo XXI editores, 1980, (6." edición).
} 
«euidado con los moros, todos sabemos su fama de traidores y de cobardes, es inherente a su raza), (Melilla Hoy, 26-III-86).

El rechazo hacia el moro es sentido por ellos mismos en Melilla, de acuerdo con las palabras de una mujer musulmana "oíamos decir a nuestro paso: "María, quítate de enmedio, que viene la mora"”, (El País, 30-III-86, p.10). Sánchez Dragó en un artículo publicado en Diario 16 (16-II-86, p. 10) habla de moras de discoteca, moritas golfas. Sin embargo, pone en boca de un cristiano «te juro por lo más sagrado [...] de que por parte española no existe ninguna actitud despreciativa hacia los moros». Una vez más parece corriente el empleo de moro en Melilla.

También podemos comprobar el carácter despectivo con el que se designa con la unidad los moros a la comunidad musulmana en afirmaciones como:

"Yo me llevo muy bien con los cristianos, musulmanes, judios e hindúes. Me llevo bien hasta con los moros, que ya es decir», (Melilla Hoy).

Resaltamos de este texto el hecho de emplear musulmanes y moros como unidades de distina referencia. Quizá sea debido a la falta de costumbre de designar con el primer término a los moros de Melilla. Asimismo debemos recordar que en épocas pasadas, en España, moro se aplicó a todos los mahometanos.

Siguiendo en el rastro del valor despectivo en el empleo de moro, encontramos la burla y el desprecio personalizados en Dudú:

«Porque está claro que el morito bueno, Dudú -nombre eufónico con aroma de chicas de Maxim's y de "La Viuda Alegre" - ha perpetrado un viaje que no figuraba en el programa [...]. España, y sobre todo Melilla, necesitan saber para qué sirve el morito Dudú», (El Alcázar, 11-X-86, p. 3).

Hay quienes descubren indicios racistas hacia el moro, sentimientos que perduran a lo largo de los siglos:

«Porque es un hecho que ese pais luchó durante muchos siglos contra los "moros" a quienes expulsó [...].

Estos mismos días ha aflorado, ante una práctica discriminatoria y racista, la 
lamentable situación en que se encuentran desde antiguo los nativos de raza no blanca en unos pequeños enclaves que ese país [...] posee en el Norte de África. [...] ni el evidente interés nacional de cuidar de esas minorias para mantener mejor la presencia nacional en esa situación en la zona, han podido vencer su multisecular racismo contra el moro [...] pues ese pueblo siempre ha jurado por su patrono, Santiago Matamoros, que no es racistan, (Melilla Hoy, 3-1-86, p. 3)

Nota peculiar es la diferencia terminológica para designar a los excombatientes del ejército español durante el mandato de Franco. Son los viejos del lugar que llegaron a Melilla en 1936 con las tropas del general Franco para incorporarse al Alzamiento.

Así, para lo musulmanes se encuentran dentro del colectivo musulmán:

«Somos hijos la mayoría de aquellos que derramaron su sangre por la patria en los años de la Guerra Civil española [...]) (Melilla Hoy, Abderramán Mohamed, 2-XI-86, p. 8).

«En la Cañada de la Muerte fue recibido [el Ministro] por un grupo de musulmanes excombatientes del Ejército español que esperaban a Barrionuevo en posición de pasar revista», (Sur, 3-1V-86, p. 15).

En El Alcázar destaca la designación de estos sujetos como marroquies

«Es llamativo, por ejemplo, que los más castigados por las dificultades para la nacionalización [...] sean los descendientes directos de los marroquies que lucharon en las filas del Ejército Nacjonal durante la Guerra de Liberación. [...] Hasta tales extremos llevan los socialistas su resentimiento y revanchismo.»

Contrastan estas designaciones con la comúnmente reconocida de «moros» incluso en la época actual, para referirse a estos excombatientes. Así en El Independiente, con motivo de la visita de Hassan II a España, en septiembre de 1986, se recogen los siguientes textos:

"El régimen anterior, con Franco como hombre de armas curtido en la guerra contra los moros, a quienes luego utilizó como tropas coloniales para su causa cuando se estableció contra el poder instituido, [...]»)

«Es sorprendente esta nostalgia del rey moro (Hassan II) hacia los usos de la dictadura de Franco y su admiración por un militar que antes de matar españoles en la guerra civil fue un "matamoros" en la guerra colonial." 
Independientemente del uso de moro para este referente concreto y centrándonos en su uso con un más amplio campo designativo, constatamos que todo el bagaje de valores afectivos encerrados en el término moro parece permanecer vigente actualmente incluso en contextos muy distintos.

Así, en el mundo laboral, la discriminación queda denunciada por los propios emigrantes marroquíes

\begin{abstract}
"Aqui nos tratan como a bestias incultas que no tenemos vida. Como a moros, y en España, moro es igual o peor que gitano".

«En Europa he visto letreros que dicen «Prohibido perros». Pero aqui el lema es «Prohibido moros». (Diario 16,27-III-89 pág. 10)
\end{abstract}

Curiosamente, en 1990, se empleará mohameds como "apelativo que usan los empresarios para referirse a los trabajadores procedentes de Marruecos y contratados de forma ilegal por no tener su situación regularizada». (El Pais, 3-VI-90 p. 16)

Con motivo de la visita del rey Hassan II a España, en septiembre de 1989, los marroquíes encontraron "groseros» y hasta «racistas» algunos chistes, titulares y editoriales periodísticos en los que se califica a Hassan II de rey «moro». A este respecto declara el hispanista Mustafá Isnassi que «todo esto expresa los peores aspectos del subconsciente español respecto al árabe. El moro sigue siendo para muchos españoles un tipo sucio y traidor.

En efecto, en El Independiente constantemente se califica a Hassan II como el «Rey moro». Curiosamente la dinastía alauita llegó en 1266 procedente de Hedjaz, provincia de Arabia. Veamos algunos ejemplos de esta denominación:

"[...] a la hospitalidad oficial que este pais ha de dispensarle muy a pesar de la pésima imagen que el Rey moro, que hoy llega a Sevilla, tiene en los ciudadanos españoles». (24-IX-89, pág. 1)

Críticas y sarcasmos relacionados con los retrasos en los horarios del monarca marroquí podemos encontrarlos en artículos de $Y a$ y de $A B C$.

Así Jaime Campany ( $A B C$ 29-IX-89 pág. 19) compara el sitio de Granada denominado «El suspiro del Moro" por Boabdil, con el palacio de la 
Moncloa «Desde entonces, a ese sitio, la puerta de la Moncloa, se la conoce con el nombre de El Retraso del Moro».

De igual manera, en el periódico $Y a$ se critican despectivamente los retrasos del rey Hassan II

"Tradicionalmente, los moros, muy alejados de la tecnología nipona del reloj de pulsera, se han orientado por la curvatura del sol para saber en qué hora vivían. Lo extraño es pensar que un Monarca como Hassan II, rico entre los ricos de este desigual planeta, recurre a los hábitos de beréberes y tuaregs para saber en qué momento de la jornada se encuentran. (27-1X-89 pág. 6)

Nos interesa destacar cómo en las declaraciones del hispanista Mustafá Isnassi, anteriormente expuestas, se producía una asimilación del moro al árabe, mientras que en el texto inmediatamente superior el moro se asocia al beréber. De nuevo nos encontramos ante el confusionismo terminológico y designativo que explicaremos más adelante. Podemos apuntar como dato curioso que en el Diccionario de sinónimos ${ }^{30}$ en la entrada moro no figura árabe como sinónimo, mientras que en la entrada árabe sí se presenta moro como sinónimo.

Recordemos que a pesar de la invasión árabe, como afirma C. Cahen ${ }^{31}$ a mediados del siglo VIII existía en España «el conjunto poco orgánico todavía, de los arabo-bereberes". Pero, aunque como ha expuesto exhaustivamente Lévi-Provençal, la población de Al-Andalus estaba compuesta por árabes, bereberes, autóctonos y esclavos, sin embargo, ya en el siglo $\mathrm{x}$ no se distinguían los musulmanes de origen árabe puro. Así reconoce LéviProvençal $^{32}$ «en el siglo $\mathrm{X}$ se puede considerar que por las venas de los árabes que se vanagloriaban de un legítimo origen qarisi o yemení [...] corría infinitamente más sangre europea o africana, o incluso negra, que asiática".

Por último, ya para lograr una más completa descripción del contenido significativo y designativo del término moro en la actualidad, debemos especificar que, según se recoge en algunas enciclopedias ${ }^{33}$, también significa «Perteneciente o relativo a un pueblo sahariano, mestizo de árabes, bereberes y negros, que habita principalmente en Mauritania». Alli, actualmente se hace la distinción entre los moros blancos (árabes y bereberes) y los moros negros. (Continuará)

${ }^{30}$ Sainz de Robles, Federico Carlos, Diccionario Español de Sinónimos y Antónimos. Madrid, Aguilar, 1978.

"Op. cit., pág. 215 y 222.

32 Op. cit., pág. 98.

3. Nueva Enciclopedia Larousse. Barcelona, Editorial Planeta, 1981. 